\title{
Creating a High Quality, High Impact CS Teacher Prep Program
}

\author{
J. Ben Schafer ${ }^{\dagger}$ \\ Computer Science Education \\ University of Northern Iowa \\ Cedar Falls, IA, USA \\ schafer@cs.uni.edu
}

\author{
J. Philip East \\ Computer Science Education, Emeritus \\ University of Northern Iowa \\ Cedar Falls, IA, USA \\ east@cs.uni.edu
}

\begin{abstract}
One of the impacts of the CS For All movement has been an increased demand for $\mathrm{K}-12$ teachers who are well-qualified to teach computer science. Unfortunately, the pool of qualified educators is much smaller than the demand, and the pipeline producing newly-qualified educators is smaller yet.

This experience report discusses the creation of a CS Education program at the University of Northern Iowa. The authors built this program with the goal of providing a standards-based, educator-focused, and peer/cohort-driven set of courses allowing both pre-service and in-service educators to become wellqualified and state-endorsed in computer science. This paper can assist institutions looking at broadening CS education on their campuses by providing both a model for the curriculum development process and sample coursework for such a program.

Additionally, this report addresses multiple lessons learned offering this new curriculum from an initial, NSF-funded cohort of "local" in-service educators, through broadening the scope to a "statewide" second cohort, to the final roll out as a full curricular program for both in-service and pre-service educators. In particular, these lessons focus on the importance of properly designed instruction, understanding the differences in the preservice and in-service audiences, and, most importantly, the strong response received to the inclusion of peer-based activities and the development of a disciplinary commons throughout the program.
\end{abstract}

\section{CCS CONCEPTS}

-Applied computing Education •Social and professional topics $\sim$ Professional topics $\sim$ Computing education $\sim$ Computing education programs $\bullet$ Social and professional topics $\sim$ Professional topics $\sim$ Computing education $\sim$ K-12 education $\bullet$ Social and professional topics $\sim$ Professional topics $\sim$ Computing education $\sim$ Model curricula

Permission to make digital or hard copies of all or part of this work for personal or classroom use is granted without fee provided that copies are not made or distributed for profit or commercial advantage and that copies bear this notice and the full citation on the first page. Copyrights for components of this work owned by others than the author(s) must be honored. Abstracting with credit is permitted. To copy otherwise, or republish, to post on servers or to redistribute to lists, requires prior specific permission and/or a fee. Request permissions from Permissions@acm.org.

SIGCSE 2022, March 3-5, 2022, Providence, RI, USA.

(1) 2022 Copyright is held by the owner/author(s). Publication rights licensed to ACM.

ACM ISBN $978-1-4503-9071-2 / 21 / 03 \ldots \$ 15.00$.

DOI: https://doi.org/10.1145/3478431.3499338.

\section{KEYWORDS}

K-12 Education, Teacher Preparation, Curriculum Development, Educator Standards

\section{ACM Reference format:}

J. Ben Schafer and J. Philip East. 2022. Creating a High Quality, High Impact CS Teacher Prep Program. In Proceedings of the 53rd ACM Technical Symposium on Computer Science Education V.1 (SIGCSE 2022), March 3-5, 2022, Providence, RI, USA. ACM, New York, NY, USA, 7 pages. https://doi.org/10.1145/3478431.3499338

\section{Introduction}

Computer Science has made significant advances in K-12 education in the last decade. For 2012, fewer than 25,000 U.S. students took the Advanced Placement Computer Science (AP CS) exam. By 2016, that number had more than doubled to 54,379 [1]. For the most recent school year, 2021, that number had increased to 166,590 test takers divided between two different AP CS exams: 63,980 completing the AP CS-A exam and 102,610 the AP Computer Science Principles exams [2,3]. Unfortunately, while the numbers of courses taught and overall students taking those courses have risen at a rapid pace, the number of educators "qualified" to teach such courses has risen at a much slower pace and school districts are facing challenges in hiring qualified teachers $[4,5]$.

In order to sustain an active culture of computer science in K12 education, we need to address the issue of teacher preparation in computer science. More specifically, we need to consider answers to questions such as what does it mean to be "wellqualified" as a computer science teacher, what should go in to the design of a computer science education program, and what elements of training are expected to have the biggest impact on the long-term success of CS teachers?

In 2016, the University of Northern Iowa (UNI) presented the authors with the opportunity to design a CS Education program almost completely from scratch. In 2018, we were awarded an NSF CSForAll:RPP grant to implement and pilot our design with a cohort of in-service teachers from the northeast portion of the state of Iowa. In 2019, this program received approval as one of only two pathways in the state by which both pre-service and inservice teachers can earn the state's Computer Science license endorsement. This paper describes our process starting from 
identifying our beliefs about such a program through the design of our final coursework. Furthermore, it addresses several of the lessons learned through multiple offerings of the program. We believe that this report can serve as a guide for those who may be interested in developing similar programs at their institutions.

\section{Program Design}

Studies have shown that the most important factor under a school's control that effects student learning is the presence of a well-prepared and knowledgeable teacher [6,7]. While this is not completely surprising, it is important to place emphasis on this concept of "well-prepared and knowledgeable." As computer science has expanded in K-12 education, it has often done so without this set of qualifiers.

As an example, most districts would not consider an English teacher well-qualified to teach HS mathematics just because the teacher completed a one-week math workshop, or even a college calculus class. Equally, districts shouldn't consider a one-week CS workshop, or a semester of college level programming, for a teacher to be "well-prepared and knowledgeable." We understand why, in an attempt to get a CS program started, districts resort to offering coursework taught by educators with limited background. However, such training is inappropriate in the long term.

With this idea in mind, we set out to design a CS education program that would make sure that teachers in our state were truly well-prepared. We did so from the starting principles that a well-prepared teacher should be able to:

1) Teach CS as currently implemented in many secondary schools (e.g., programming, AP CS-A and AP CSP)

2) Respond to student discussions/questions about current "hot" topics (big data, AI, machine learning, etc.)

3) Engage students in issues surrounding security, privacy, and other social issues

4) Add new CS courses to their curriculum as the discipline rises in demand in their school

5) Willingly expand their knowledge of CS and respond to new developments in the discipline

To ground our development, we began the design process by considering several programs in computer science teacher prep; in particular, we studied the graduate programs at the College of Saint Scholastica [8], the University of Nebraska at Omaha [9], and a specialized program at Stanford University [10]. We did so looking for ways that these existing programs taught coursework that aligned with our five principles. Unfortunately, at the time we were unable to find public examples of full programs focusing on undergraduate, pre-service teachers.

While these comparables helped us to get started with our process, in the end we largely created our program from scratch. We decided we wanted a program that would be:

1) Standards-based: Curriculum design emphasizes specific outcomes and standards in mind.

2) Educator-based: Curriculum design emphasizes an audience of educators and is not by using courses already existing for CS majors.
3) Peer/cohort-based: Curriculum design and course activities place an emphasis on collaboration and developing a community of practice.

\subsection{Standards-Based}

We are strong proponents of "Understanding by Design" (UBD) as a process for Instructional Design [11,12]. The UBD process (sometimes referred to as "backwards design" or "backward planning") follows a three-step planning sequence:

1) Identify Desired Learning Results

2) Determine Acceptable Evidence

3) Plan Learning Experiences and Instruction

When we started the design of our program, we wanted to have a clear set of learning results from which to work. In other words, design should be driven by outcomes not content.

The first goal we had was connecting our instruction for educators to the standards required of their students. That is, we wanted to address the national and local CS standards for K-12 students. This involved linking our program design to the K-12 CS Framework (formally published in 2016) [13] and the CSTA K12 CS Standards (formally published in 2017) [14]. Among those states that have formally adopted K-12 CS standards, most have either adopted these CSTA Standards in their entirety or implemented them with minor adjustments/additions.

However, being a well-qualified educator means more than just being able to teach to student standards. There are additional skills and attributes necessary for well-qualified teachers. In 2011, ISTE (International Society for Technology in Education) published the "ISTE Standards for Computer Science Educators" [15]. These begin with knowledge of content, but include standards addressing, effective teaching and learning strategies, effective learning environments, and effective professional knowledge and skills. We based our design on the 2011 version of these because we felt these were stronger and specifically focused on observable/assessable outcomes versus those released in the modified 2017 standards.

The inclusion of these standards in the development of our program allowed us to ensure that we were giving educators access to not only content, but also the ways and means for them to help their students access this content.

\subsection{Educator-Based}

As we built our curriculum, we were committed to the belief that educators should receive training designed specifically for educators. Rather than asking teachers to take courses developed for majors, we designed a program in which the structure of each course was organized to train well-qualified educators.

This is not a new concept. As an example, the Mathematics Education BA at UNI requires 51 total credits in mathematics (in addition to the education courses taken in the College of Education). At least 18 of these credits are in courses specifically designed for pre-service teachers. Similarly, the STEM education certificate consists of 34 credits from which, depending on student choices, anywhere from 16 to 28 of these credits are designed for 
pre-service teachers. Despite this, many CS programs seem to take the approach of mostly using existing, major-based courses.

What does it really mean for a course to be educator-based? In our program, it means carefully selecting the examples used, paired with early, frequent, and active discussion about issues of teaching and learning and doing so across all of our courses. We will discuss this first point further in the Lessons Learned section of the paper, but we believed - and have found to be true - that the motivating topics and examples are significantly different between CS majors and those on a CS education track. We felt it was important to be aware of these distinctions and wanted to create coursework independent of that taken by traditional majors. As to this second point, we believed that discussions about teaching and learning must be deliberate and focused. This cannot be accomplished while asking students to take an Introductory Programming or CS0 overview course intended for CS majors. Instead, we wanted to develop our courses so that such activity was woven into the program from the very first course.

\subsection{Peer/cohort-Based}

We were very concerned about battling any sense of isolation among the participants in our program - in particular among inservice teachers who often complete the program largely online and from school districts where they frequently have few peers for support. As a comparison, an in-service math or science teacher pursing additional training in their discipline most likely can walk across the hall to talk through ideas with a colleague with similar backgrounds. CS teachers often have no access to peers with related background. For them, the ability to reach out for help, or even just to vent, is often limited or even non-existent.

In order to confront this challenge, we elected to design our program so that it heavily relies upon the development of "communities of practice." Such communities promote a sense of belonging by including the concept of ongoing collaboration about teaching materials and teaching design. Psychology research states "engagement in social practice is the fundamental process by which we learn and so become who we are." [16]. CS educational researchers have applied this concept through the use of the "Disciplinary Commons" to "document and share knowledge about teaching and student learning in Computer Science classrooms" and as a means to support existing CS teachers by encouraging active discussion about teaching, and provide a sense of community $[17,18]$.

We used these ideas in our program to design experiences that would connect the members of the class not only in the short term - during the actual timeframe of the course - but also in the long term; as supportive peers beyond the timeframe of our program. We want educators to have opportunities to collaborate on the development and review of teaching materials and have access to those materials beyond the scope of their program. As will be discussed further in this report, we feel that this was arguably the most important decision we made in our program development. The peer relationships that they formed in our program have provided them with a support network - both personally and professionally - that has been vitally important.

\section{Curriculum}

Using the various issues discussed in the previous section, we developed five, three-credit courses. Each of these courses is carefully aligned to the CSTA and ISTE standards previously discussed with each standard addressed during at least one course, and often multiple times across the curriculum. Unfortunately, publishing the full standards crosswalk is beyond the scope of this paper.

In the following sub-sections, we briefly introduce each of the five courses. With each, we specifically address how the course aligns with our goals of coursework that is standards-based, educator-based, and peer-based instruction.

\subsection{Fundamentals of Programming}

While, comparable to the CS1 course taught to majors in many CS departments, Fundamentals of Programming (FOP) is designed around the understanding that educators are the primary audience. The course places less emphasis on "learning to become a programmer" and more emphasis on "what are the elements of programming?" as well as "what are the things that a teacher or a student might want/need to do via programming?" The course is divided into two distinct phases. In the first five weeks, students learn the fundamentals elements of computer programming by interacting with a graphical programing language (Scratch). During this stage of the course, the focus is on the concepts, vocabulary, and structure of programming. For the remaining ten weeks of the course students translate and expand these fundamentals to a text-based language (Python). During this stage of the course, the focus is on the use of the computer as a tool for problem solving and data analysis.

This emphasis on "problem solving" is a conscious design element of the course. For each new topic, students receive 1-3 small problems. They consider what they currently know that will help them program the computer to assist with the problems and identify what concepts are missing from their knowledge base. The instructor then introduces these new/missing concepts both within the context of solving the presented problems but also in a general-purpose manner. Once the new material is "learned," students apply the concepts to additional problems, first in a paired programming scenario and finally, on their own.

In this course, we promote peer relationships through the ongoing use of paired programming and "peer review" of code. We utilize the concept of a Disciplinary Commons through the inclusion of two activities where students create and peer-review programming activities for the classroom. These activities seed a repository of materials that remain publicly available to the students upon the completion of the course. Beyond peer connections, this type of activity has proven popular due to the level of student self-choice present in the assignments.

\subsection{Foundational Concepts of Computer Science}

The Foundational Concepts of Computer Science (FCCS) course examines the breadth of the field of computer science beyond programming of the computer. The course addresses 
many of the non-programming topics that are part of AP CSP coursework and is comparable to a breadth-first/CS0 course taught in some departments. In fact, the course currently draws heavily from the popular Brookshear and Brylow textbook used in many CS0-like courses taught across the country [19]. However, our course design differs from many of the majorsoriented courses in both the selection of the specific topics of study, the depth of knowledge expected about these topics, and the amount of time spent on ethics and societal impacts surrounding these topics.

We have designed this course so that students spend an appreciable amount of knowledge acquisition on their own time. They achieve this through the completion of weekly readings, video "lectures" utilizing the Crash Course Computing series, interaction with online resources, and participation in small group study/discussion sessions. In these sessions, groups test and broaden their knowledge through collaboration centered on a set of questions which range from fully right/wrong fact-based questions to extremely open-ended questions discussing scenarios such as "who is to blame?" and "how would you convince your students that...?" These questions and the student responses to them focus much of the remaining interactions between instructors and the class.

At this time, this course does not create additional material for the Disciplinary Commons that lives beyond the end of the course. However, this is one of the top priorities for future revision of the course.

\subsection{Teaching and Learning Programming}

The course is a further study of computer programming, but it is framed within the context of taking a deep dive into the structure and process of programming along with what educators can do to help students learn. While some topics (such as an understanding of code quality) is often part of a traditional CS program, most of this course is the furthering of programming skills within the framework of teaching and learning programming itself. Thus, Teaching and Learning Programming (TLP) allows us to cover some of the elements that might be covered in a traditional CS1 course but really begin to prepare our students as CS educators.

As with prior courses, the TLP course contains very few traditional "lectures." Instead, students come to class having completed a set of preparation readings. They spend several class days discussing and preparing small group documents based on the topics in these readings. Many of these documents are created for contribution to the Disciplinary Commons. These include a "good code primer" ("a document you could use with students to explain/illustrate good and bad code"), a manifesto about beliefs of teaching and learning, and the plan for a programming unit based on a subset of standards and designed within the context of supportive practices.

\subsection{Data Structures and Algorithms}

While there are certainly elements of traditional CS2 (data structures) and algorithms courses for majors in the design of the
Data Structures and Algorithms (DSA) course, we felt that the typical coverage of topics in a course for majors was misaligned with our expectations for a secondary CS teacher. We expect teachers to be familiar with a variety of issues from these courses, but expect that the outcomes and assessments of this material used with educators should be quite different from those of a student electing to major in computer science.

While we begin the course with a traditional coverage of searching and sorting algorithms, the majority of the course has evolved to be themed to an educator-level coverage of artificial intelligence. This is achieved by combining many of the discussions of data structures within the consideration and analysis of traditional AI algorithms. For example, queues, stacks, and ordered lists/queues are studied within the context of breadth first, depth first, and $A^{*}$ algorithms respectively. Tree structures are introduced within the context of machine learning algorithms and natural language search techniques.

Because major elements of this course are assessed at the level of "familiarity" rather than "proficiency," much of this course is spent in small groups reading and analyzing provided pseudocode algorithms and making (non-graded) attempts at translating these to workable code. Most of these teachers will never directly teach these concepts but may only indirectly teach them in the student "performance tasks" from the AP CSP exam or in more "advanced" courses such as those focusing on game design or app development. Specific student choices or annual community partners heavily influence all of these courses. Thus, a general knowledge of the wide range of data structures and traditional algorithms is helpful.

This course contains one of the largest, and perhaps most popular of the Disciplinary Commons projects. At the end of the course, students divide a list of common data structures and algorithms. Some of these are topics that they encountered during the course while others are new (e.g. The Floyd-Warshall algorithm, set partition and the knapsack problems.) Students collaborate to research these topics and create an encyclopedic reference document that explains each concept and discusses ways in which it might show up in a high school CS classroom. This reference is created in a collaborative Google document and becomes an educator-written, crowd-sourced resource for their future needs.

\subsection{Methods of Computer Science}

In the Methods course, participants learn effective strategies for teaching computer science at multiple levels and with a focus on different course topics/types. In other words, this course is similar to a methods class in virtually any educational discipline where the goal is to focus on the theory and practice of teaching in a specific content area. However, the development of this course was probably the hardest for us of all of these courses. There were few public examples of CS Methods courses available online. Fortunately, for future developers a group of CS Education faculty has since presented a panel detailing various CS Methods courses as part of the 2021 SIGCSE TS conference [20].

The first half of our course covers specific content topics such as the study of CS as a K-12 discipline, specific teaching method 
frequently employed in CS, and issues about supportive practices and equitable grading as part of the curriculum design process. However, the real emphasis of the course happens in the second half. Students collaborate to develop a relatively complete curriculum design following the "Understanding by Design" process. Teams of teachers offering similar classes collaborate to complete a four-part design focusing on the identification of outcomes, developing assessments based on those outcomes, creating sample learning activities, and developing a grading procedure.

Once again, these designs are available to all participants beyond the completion of the course through publication in our Disciplinary Commons. This too has been one of the mostappreciated elements of our program as it has given students concrete materials to use beyond their coursework.

\section{Lessons Learned}

At this point, we have completed our program with two cohorts of in-service teachers resulting in 41 newly endorsed teachers in Iowa. Additionally, we are currently in process with two groups: one being a third cohort of in-service teachers and the other being our first group of undergraduate/pre-service teachers. So far, this process has taught us a lot that has both validated some of our original beliefs as well as forced us to reconsider some of our assumptions about how to best address these beliefs. In the following, we discuss four lessons learned. Upon the surface, none of these lessons are particularly surprising. However, the degree to which each lesson presented itself was the surprising part. We feel it is helpful to share a bit of reflection upon these top four lessons.

\section{Lesson 1: Educator motivation is different from "majors" motivation.}

In a discussion that began earlier in this paper, we claimed that educators would require different motivating examples compared to those used with CS majors. This fact has been observed frequently in our initial work.

A major aspect of this relates to why students are taking coursework. CS majors typically K $\Xi$ hुto be in the major. They may not always fully understand what computer science is and means, but they have mostly made a conscious and deliberate decision to get a degree in computer science. For them, examples that illustrate the workings of the computer are often highly motivating. However, this is frequently not the case in CS education programs. In-service teachers have often been "coerced" by their school districts to pursue an endorsement in computer science. In Iowa, a 2020 law requires that all high schools must offer at least one computer science course by the fall of 2022. While an endorsement is not required for this mandate, many districts recognize that they want to have a qualified teacher in such a position. As such, an increasing number of districts have asked (or told) teachers to pursue a CS endorsement. While the rate of "self-selection" is a little bit higher among our preservice/undergraduate students, we still find that many have been strongly encouraged by a family member or an advisor to consider adding a CS endorsement on top of their primary major. For example, the advisors in the business department at UNI have started encouraging all business teaching majors to add a CS endorsement to make themselves more marketable, to align themselves better for Career and Technical Education (CTE) positions, and to make them, and their future employer, more eligible for Perkins funding.

We have found that in-class programming assignments, structure for high level thought questions, and even the metaphor examples to frame explanations of the working of the computer need to be carefully selected and offer differ significantly from the ones used in a majors-based course.

Lesson 2: While the content stays the same, the presentation and discussion of content differs significantly between pre-service and in-service teachers.

While it is expected that there are differences between undergraduates and graduate students, it turns out that there are much larger differences than simply maturity and teaching experience. Some of this is the routine differences between teaching to on-campus, residential, primarily single, full-time students vs. teaching to off-campus, online, family members, who are taking courses, often while working full-time (and in some cases, multiple) jobs.

With pre-service, on-campus students we were able to develop a schedule based on the idea that students are (at least in theory) present in the classroom on a regular and consistent schedule. Content can be divided into manageable chunks, and the passage of time keeps the students mostly on schedule. Careful planning can utilize class time for collaborative group work. The majority of students will do a good job staying on track.

With in-service, off campus students, however, there are many factors in play. While the "easiest" way to teach to these participants will use online and frequently asynchronous material, this is frequently a less effective strategy. Students have more forces competing for their time and will often put off even beginning activities until last-minute deadlines loom large - even more so than undergraduates. This results in cramming together a week's worth of lectures and activities into a single, weekend afternoon or late-evening. Students need the presence of synchronous or group-based work to keep them on track. Furthermore, they need a structure that gives them sufficient time to successfully process and complete the content in a course.

It may help to illustrate this by using a specific example, from our experiences with our first cohort. With this group of participants, we taught FOP as an 8-week summer course. This proved to be too much material for this timeframe, despite the fact that students had the "freedom" of taking this course while not actively teaching full time. In hindsight, we should have seen this coming. Most of us tell our students to start assignments early so if they hit a wall they can walk away and come back fresh the next day. In a compressed, 8-week summer course we were asking students to complete at least one, and sometimes two or three, programs per weekday. This structure failed to adequately allow for the scenario of reaching a sticking point and walking away to just think about it. Students were much more successful when we 
moved the course to the fall semester with Cohort 2. Even though they were completing our course while teaching full time and raising families, they had the opportunity to encounter a problem and walk away to reflect.

As a side note, we have become increasingly attuned to the challenges faced by in-service teachers. It is important to consider the amount of time required for a course and how it is competing against the other life/time distractions present with this. We feel strongly that we do not want to cheat in-service teachers of a high-quality education, but we also recognize that they are completing much of this coursework while working and raising families. As such, it takes a careful balance of time allotted for the completion of a particular course. Timing and scheduling matter greatly.

Lesson 3: Discussions about teaching and learning differ greatly between pre-service and in-service teachers.

Of all the differences we experienced between our two audiences, this may be the one that has the most impact on future course designs.

Pre-service teachers need far more time than we expected to consider and discuss teaching practices and classroom issues. Despite having been students for 13-plus years, they are not accustomed to thinking about teaching and learning. For them, this is largely an exercise in theoretical thinking rather than practical analysis. They often need very specific, framed discussion questions asking about explicit scenarios in hypothetical classrooms. They also struggle with the process of developing course materials due to their lack of experience. They are not unwilling or afraid to tackle these activities, but their lack of experience makes it a slow process. In the end, we learned we had to consider these activities more for the practice of the process than we did for the formal products produced.

In-service teachers, on the other hand, need very little prompting to relate any discussion, whether based on content or pedagogy, back to their classroom. They are quick to tell you their own experiences and to challenge material if it doesn't match often to the point of making teaching pedagogy a challenge. In particular, those with extensive teaching but in non-CS disciplines often have a difficult time understanding why student interaction and exploration with CS might differ from other disciplines. Despite this, in-service participants repeatedly tell us how much they appreciated class activities that either are directly applicable to their own classrooms or allow them to produce such activities and lesson plans.

Lesson 4: Peer-based activities are the most difficult thing to start, but arguably the most beneficial activities to student growth.

We knew from the very start that we wanted, even needed, to encourage peer relations in our coursework. Nevertheless, the degree to which the participants in our first two cohorts emphasized the benefits of this element caught us by surprise. In particular, this is because students (especially online students) initially resist the requirement to complete group work. Several of our in-service teachers were already familiar with online graduate PD conducted almost entirely in isolation. They were comfortable with this and appreciated the anonymity and the ability to work entirely at their own pace (since no classmates were dependent on them being ready by a specific date). Despite this initial hesitation, external evaluations conducted as part of our NSF grant showed participants overwhelmingly came to appreciate the cohort nature of the program and the materials that they produced as part of the Disciplinary Commons.

As we noted before, teachers are often in districts where there may be no colleague with training like theirs. They reported how much they appreciated the relationships with peers who they could rely on for support both emotionally and with materials (asking questions, sharing materials, etc.). They indicated that they continue to rely on those relationships a full year after the program has ended. In fact, participant data analysis shows that those who spent the most time working in and with a community of peers were 1) happier with the program, 2) more confident in their abilities, and 3) able to earn higher grades or show greater competency on class activities.

While the Disciplinary Commons materials were not a major element of our original designs of the courses, these materials have proven to be incredibly popular both during and after the completion of the various courses. Analysis of access logs has shown that many in-service teachers have returned to the collection of programming assignments created by their peers as a way to find ideas or already completed activities for their programming-based classes. Similarly, the DSA reference document appears both anecdotally and through usage logs as a valuable resource to a small but active subset of program participants, with access well over a year after its writing. As a result, the Disciplinary Commons has developed to be an increasingly important element across our program.

\section{ACKNOWLEDGMENTS}

The authors would like to acknowledge Dr. Sarah Diesburg for her assistance in developing and teaching courses in the early stages of the program, Dr. Dana Atwood-Blaine for her role with developing early evaluation materials for the program, and Drs. Briana Morrison and Michelle Friend who served as external reviewers under the NSF grant. Their guidance at multiple stages is greatly appreciated.

\section{REFERENCES}

[1] Barbara Erickson. 2016. Analysis of 2016 AP Computer Science Testing Reveals Ongoing Need for Qualified High School Teachers. Retrieved December 20, 2016 from http://www.scs.gatech.edu/news/584765/analysis-2016-apcomputer-science-testing-reveals-ongoing-need-qualified-high-school

[2] Trevor Parker. 2021. AP Computer Science A Exam: 2021 Results. Retrieved August 10, 2021 from https://allaccess.collegeboard.org/ap-computer-scienceexam-2021-results.

[3] Trevor Parker. 2021. AP Computer Science Principles: 2021 Results. Retrieved August 10, 2021 from https://allaccess.collegeboard.org/ap-computer-scienceprinciples-2021-result

[4] Esther Shein. 2019. The CS Teachers Shortage. Communications of the ACM, October 2019, Vol. 62 No. 10, 17-18. DOI: https//doi.org/10.1145/3355375

[5] Emiliana Vegas and Brian Fowler. 2020. What do we know about the expansion of K-12 computer science education?. Retrieved August 10, 2021 from https://www.brookings.edu/research/what-do-we-know-about-the-expansionof-k-12-computer-science-education/ 
[6] Raj Chetty, John N. Friedman, and Jonah E. Rockoff. 2014. Measuring the Impacts of Teachers I: Evaluating Bias in Teacher Value-Added Estimates. American Economic Review. Vol 104, No. 9, September 2014. pp 2593-2632.

[7] Raj Chetty, John N. Friedman, and Jonah E. Rockoff. 2014. Measuring the Impacts of Teachers II: Teacher Value-Added and Student Outcomes in Adulthood. American Economic Review. Vol 104, No. 9, September 2014. pp 2633-2679.

[8] College of St. Scholastica Certificate in Computer Science Education. Retrieved August 10, 2021 from http://www.css.edu/graduate/masters-doctoral-andprofessional-programs/areas-of-study/master-of-education-(med)/certificatein-computer-science-education.html

[9] University of Nebraska Omaha, MS in CS Education. Retrieved August 10, 2021 from https://www.unomaha.edu/college-of-information-science-andtechnology/ computer-science-education/graduate/ms-csed.php

[10] Stanford Engineering Computer Science Master's Degree in Computer Science Engineering. $\quad$ Retrieved August 10, 2021 from https://cs.stanford.edu/people/eroberts/mscsed/AdmissionsMSInCSEducation.html

[11] Jay McTighe. 2019. The Fundamentals of Backward planning. Retrieved August 10, 2021 from https://www.ascd.org/el/articles/the-fundamentals-ofbackward-planning

[12] Ryan Bowen. 2017. Understanding by Design. Vanderbilt University Center for Teaching. Retrieved August 10, 2021 from https://cft.vanderbilt.edu/understanding-by-design/
[13] K-12 computer Science Framework. Retrieved August 10, 2021 from https://k12cs.org/

[14] CSTA K-12 CS Standards. Retrieved August 10, 2021 from https://www.csteachers.org/page/standards

[15] ISTE Standards for Computer Science Educators, 2011. Retrieved December 5 , 2021 from https://www.ohiohighered.org/sites/default/files/ISTE\%20Standard \%20for\%20Computer\%20Science\%20Educators\%202011\%20\%28Permitted\%20Ed ucational\%20Use\%29.pdf

[16] Etienne Wegner. 1998. Communities of Practice: Learning, Meaning, and Identity.” Cambridge University Press. https://doi.org/10.1017/CBO9780511803932

[17] Tenenberg, Josh.and Sally Fincher. Opening the door of the computer science classroom: The Disciplinary Commons. ACM SIGCSE Bulletin, Volume 39, Issue 1, March 2007. Pp 514-518. https://doi.org/10.1145/1227504.1227484

[18] Lijun Ni, Mark Guzdial, Allison Elliott Tew, Briana Morrison, and Ria Galanos. (2011). Building a Community to Support HS CS Teachers: the Disciplinary Commons for Computing Educators." In Proceedings of the 42nd ACM technical symposium on computer science education. pp. 553-558. New York, NY, USA: ACM. doi:10.1145/1953163.1953319.

[19] Glenn Brookshear and Dennis Brylow. 2019. Computer Science: An Overview (13 ${ }^{\text {th }}$ Edition). Pearson Press.

[20] Michelle Friend, Anne Leftwich, J. Ben Schafer, Beth Simon, and Briana Morrison. 2021. Panel:Teaching the Methods of Teaching CS. In Proceedings of the $52^{\text {nd }} A C M$ technical symposium on computer science education. pp 459460. https://10.1145/3408877.342573 